\title{
ВЛИЯНИЕ КРУТИЛЬНЫХ И ПРОДОЛЬНЫХ КОЛЕБАНИЙ НА СКОРОСТЬ БУРЕНИЯ И ОБРАЗОВАНИЕ ПОЛОМОК РЕЖУЩИХ ЭЛЕМЕНТОВ БУРОВЫХ ДОЛОТ, АРМИРОВАННЫХ РОС
}

\author{
Третьяк Александр Александрович', \\ 13050465@mail.ru
}

\author{
Литкевич Юрий Федорович', \\ 13050465@mail.ru
}

\author{
Борисов Константин Андреевич', \\ 13020165@mail.ru
Южно-Российский государственный политехнический университет (НПИ) им. М.И. Платова, Россия, 346428, г. Новочеркасск, ул. Просвещения, 132.

\begin{abstract}
Актуальность. В настоящее время для сооружения скважин на нефть и газ наиболее эффективным инструментом являются долота, армированные пластинами PDC (polycrystalline diamond cutters). Такие долота работают по принципу резания-скалывания, так как из всех механизмов разрушения породы резание является наиболее эффективным по причине того, что прочность породы на растяжение и скол значительно меньше её прочности на сжатие. Анализ состояния отработанных буровых долот, армированных пластинами PDC, показывает, что они отрабатывают свой ресурс не полностью, так как часть режущих РDС элементов выходит из строя по причине скола. Многообразие форм сколов по форме и размерам требует провести классификацию, выявить причину появления и определить нагрузки, приводящие к их возникновению. Кроме того, слом пластин или их потеря в значительной степени сказываются на конечных технико-экономических показателях бурения разведочных и эксплуатационных скважин. Решение вопросов повышения качества долот путем уменьшения числа поломок будет способствовать повышению экономической эффективности работ при добыче и разведке полезных ископаемых.

Целью исследования является определение размеров площадок скола пластин PDC для дальнейшей классификации в зависимости от толщины срезаемого слоя породы, причин возникновения крутильных и продольных колебаний в бурильной колонне, вызывающих поломки PDC, а также разработка конструкции бурового долота, армированного пластинами PDC, предупреждающего появление автоколебаний в бурильной колонне.

Объекты: режущие элементы буровых долот, армированных пластинами PDC с плоской передней гранью и PDC с выпуклой передней гранью, сколы пластин PDC на буровых долотах, возникающие в процессе бурения скважин.

Методы: экспериментально-аналитический метод исследования на лабораторных образцах и на отработанных буровых долотах, армированных пластинами PDC.

Результаты. На основании анализа и обобщения результатов выполненных лабораторных исследований причин возникновения поломок пластин PDC и их характера разработан ряд технических и технологических решений, предупреждающих возникновение крутильных и продольных автоколебаний в бурильной колонне и повышающих эффективность породоразрушающего инструмента, армированного пластинами PDC.
\end{abstract}

\section{Ключевые слова:}

Лабораторные исследования, отработанные буровые долота, поломки PDC, крутильные колебания, скол от действия сил по передней грани, скол от действия сил по задней грани, крутильная волна, продольная волна, энергия неупругого удара, разведка полезных ископаемых.

\section{Введение}

Бурение скважин на нефть и газ в комплексе работ при геологоразведке выходит на первое место как по стоимости работ, так и по качеству и количеству геологической информации, получаемой в ходе их проведения. Эффективность процесса бурения скважин, особенно в твердых породах, в значительной степени определяется эксплуатационными показателями породоразрушающего инструмента.

В настоящее время наиболее эффективными являются долота, армированные PDC (polycrystalline diamond cutters), которые при бурении по породам до IX категории по буримости обеспечивают увеличение проходки в 1,5-2 раза по сравнению с трехшарошечными долотами в одинаковых геолого-технологических условиях [1-5].

Наработка буровых долот, армированных PDC, зависит от износа и поломок режущих элементов. На каждом из отработанных долот количество из- ношенных и поломанных режущих элементов примерно одинаково. Анализ состояния отработанных долот показывает, что поломки PDC имеют преимущественно два вида: а) сколы от действия сил со стороны передней грани, б) сколы от действия сил со стороны задней грани, также встречаются отрывы пластин. На рис. 1 показаны основные виды поломок. Размеры сколов можно характеризовать площадью поверхности сколов $S_{\text {ск }}, \mathrm{MM}^{2}$. На рис. 2 показаны PDC до и после образования скола в лабораторных условиях.

\section{Задача}

Анализ имеющихся экспериментальных данных, полученных в лабораторных условиях [6-8] и на отработанных долотах, показал, что все многообразие поломок можно разделить на группы в зависимости от их размеров и площади скола $\left.\left(S_{\text {ск }}\right): 1\right)$ мелкие сколы; 2) средние сколы; 3) крупные сколы. 
Площади сколов $\Sigma S$ можно рассматривать как образование дополнительных площадок затупления, определяющих удельную нагрузку на режущих кромках PDC.
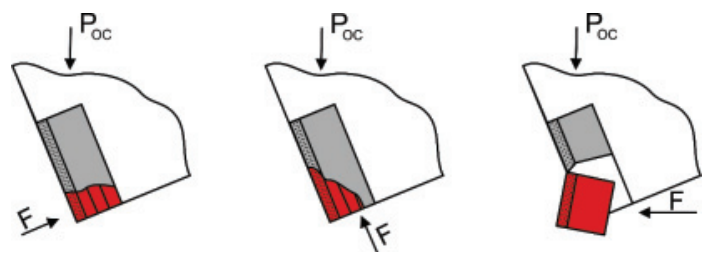

Pис.1. Основные виды поломок пластин PDC (слева направо): сколы от действия сил со стороны передней грани; сколь от действия сил со стороны задней грани; отрыв пластины

Fig. 1. Main types of damages to the PDC plates (from left to right): breakdown from the action of forces from the front face; breakdown from the action of forces from the rear face; plate detachment

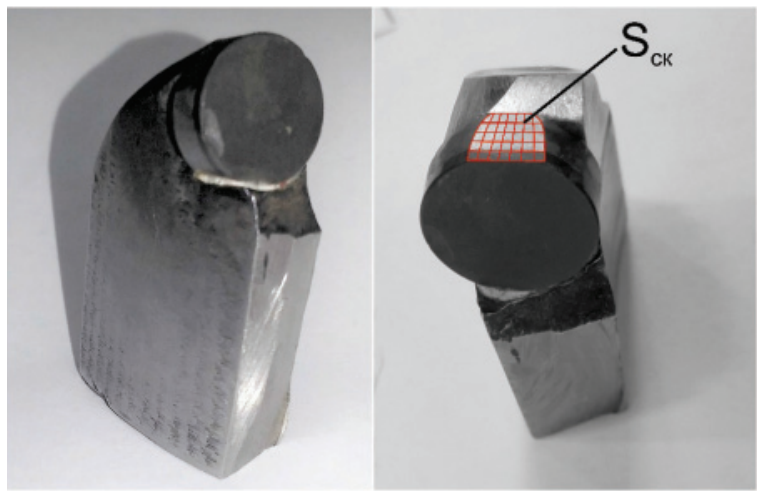

Pис. 2. Элемент долота с пластиной $P D C$ до и после образования площадки скола $S_{\text {ск }}$ в процессе лабораторных исследова ний

Fig. 2. Bit element with PDC plate before and after the formation of $S_{\mathrm{ck}}$ breakdown area, in the laboratory research

Прочностные характеристики режущих элементов значительно превышают прочностные характеристики буримых пород. Так, у твердосплавной основы PDC твердость 96-91 HRA, прочность на изгиб - до $1800 \mathrm{MПа,} \mathrm{а} \mathrm{у} \mathrm{алмазного} \mathrm{слоя} \mathrm{предел}$ прочности при сжатии - 2000 МПа. Следовательно, поломки могут происходить только от действия ударных нагрузок.

Изменения по величине сил резания и крутящего момента на долоте приводит к возникновению крутильных колебаний на буровой колонне. Исследованиями $[9,10]$, проводимыми при бурении скважин глубиной 1800 м бурильной колонной из труб $\varnothing 127$ мм долотом БИТ2 Ø214 мм при крутящем моменте на долоте $9 \kappa \mathrm{H} \cdot \mathrm{м}$ и частоте вращения, равной 120 об/мин, установили, что буровая колонна закручивается на 5,6 оборота, а при уменьшении крутящего момента до $6 \mathrm{kH} \cdot \mathrm{m} \mathrm{pa-}$ скручивается на два оборота. Такое изменение углов закручивания бурильной колонны запускает процесс крутильных автоколебаний. Их период $T$, определяемый по формуле (1), составит 3 секунды, а число колебаний $v$, определяемое по формуле (2), будет равно 20 колеб/мин.

$$
\begin{gathered}
T=\frac{4 l}{\lambda} \mathrm{c}, \\
v=\frac{15 \lambda}{l} \text { колеб/мин, }
\end{gathered}
$$

где $l=1800 \mathrm{~m}$ - длина бурильной колонны; $\lambda=2465 \mathrm{~m} / \mathrm{c}-$ скорость распространения крутильных возмущений.

Это значит, что каждые 3 секунды на долото будет воздействовать один ударный импульс от автоколебаний. И хотя вероятность образования разрушающего удара на PDC не высока (менее $20 \%$ ), $P \leq 0,2$, анализ причин выхода из строя отработанных долот показывает, что число поломок и нормально изношенных PDC на долоте примерно одинаково.

Так, по данным [11], при бурении скважины глубиной 1560 м по крепким породам VIII категории буримости с $P_{\mathrm{r}}=960 \mathrm{MПа} \mathrm{долотом} \varnothing 215,9 \mathrm{MM}$ и с лопастями, вооруженными 56 пластинами PDC, средняя скорость бурения составляла $10,5 \mathrm{M} /$ ч.

При этом на отработанных долотах более $15 \%$ режущих элементов PDC имели поломки различных видов. Это значит, что решение задачи по уменьшению крутильных колебаний, приводящих к возникновению поломок PDC, является актуальной.

Кроме того, крутильные колебания опасны еще и тем, что они порождают развитие сильных продольных колебаний [12-15]. Колебания этого рода вызывают поломки породоразрушающего инструмента от действия сил по задней грани $[16,17]$.

Условием резонанса продольных автоколебаний, вызванных крутильными, будет равенство собственных частот крутильных $\left(W_{\mathrm{k}}\right)$ и продольных $\left(W_{\text {п }}\right)$ колебаний, т. е. должно соблюдаться условие:

$$
W_{\mathrm{\kappa}}=W_{\text {п }} .
$$

Для образования продольных автоколебаний, возникающих в результате крутильных, необходима строгая синхронизация собственных крутильных и продольных частот породоразрушающего инструмента, то есть частота продольных резонансных колебаний $v_{\text {рез }}$ равна продольной круговой частоте $W_{\text {к.рез }}$, поделенной на $2 \pi$. В результате этого получаем:

$$
v_{\text {рез }}=\frac{W_{\text {к.рез }}}{\lambda \pi}=\frac{1}{2 \pi} \frac{k \lambda \pi}{2 l_{\text {рез }}},
$$

где $v_{\text {рез }}$ - частота продольных резонансных колебаний; $l_{\text {рез }}$ - резонансная длина колонны; $k=1,2,3$ числа натурального ряда.

Продольные автоколебания могут начинаться только лишь с некоторой определенной глубины скважины. Причем частота продольных автоколебаний $v_{\text {рез }}$, начиная от максимального значения при глубине примерно 40 м, убывает до минимального - 25 Гц, с увеличением длины бурильной ко- 
лонны $l_{\text {рез }}$. По данным [18-20], расчёты взаимосвязи резонансных длин $l_{\text {рез }}$ и частот $v_{\text {рез }}$ бурильной колонны в случае продольных автоколебаний, выполненных по формуле (3), представлены графически на рис. 3.

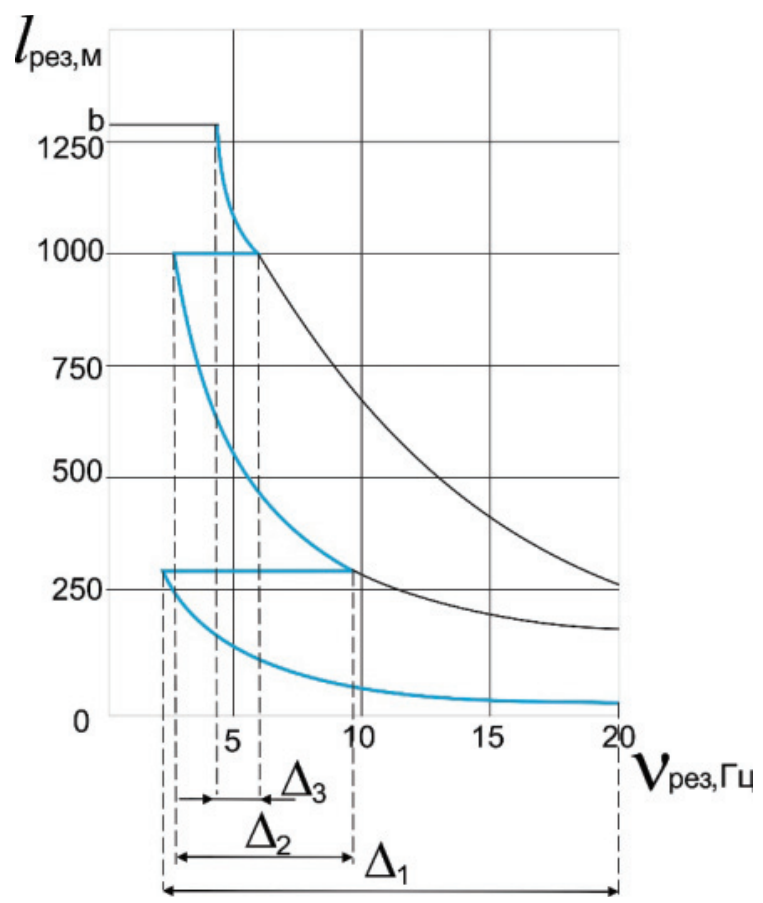

Pис. 3. График взаимосвязи резонансньх длин и частот бурильной колонны в случае продольных автоколебаний

Fig. 3. Graph of relationship of resonant lengths and frequencies of the drill string in the case of longitudinal self-oscillations

Из графика видно, что с увеличением глубины

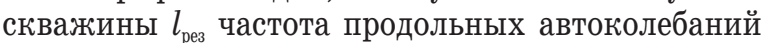
$v_{\text {рез }}$ уменьшается.

В моменты наступления равенства частот крутильных и продольных колебаний возникают предпосылки для их совместного воздействия на заднюю поверхность режущих пластин $\mathrm{PDC}$, приводящих к образованию сколов по задней грани.

\section{Решение}

Анализ имеющихся экспериментальных данных на обработанных долотах показал, что все многообразие поломок можно разделить на группы в зависимости от их размеров и площади скола $S_{\text {ск }}, \mathrm{Mm}^{2}$ : $1)$ мелкие сколы, где $S_{\text {м.ск }} \approx 9-18$ мм² $^{2}$. К этой группе относятся около $60 \%$ всех поломок (58-60\%);

2) средние сколы, $S_{\text {ср.ск }} \approx 19-30 \mathrm{Mm}^{2}$. В этой группе находятся около $30 \%$ поломок (27-30\%);

3) крупные сколы, $S_{\text {кр.кк }} \approx 31-42$ мм $^{2}$. К ним относятся примерно $10 \%$ поломок (10-12\%).

На рис. 4 показана схема образования сколов при различных значениях $B$ (мм), $h$ (мм) и $S\left(\mathrm{Mм}^{2}\right)$ для пластин $\mathrm{PDC}$ радиусом $R=7,75$ мм. В таблице приведено разделение сколов по группам в зависимости от $S$.
Площадь сколов $\Sigma S$ можно рассматривать как образование дополнительных площадок затупления, определяющих удельную нагрузку на режущих кромках PDC. Тогда, например, зная процент поломок, можно рассчитать вероятную скорость бурения.

таблища. Разделение сколов по группам

Table. $\quad$ Split breakdowns intogroups

\begin{tabular}{|c|c|c|c|}
\hline & \multicolumn{2}{|c|}{$B=2 \sqrt{2 R h-h^{2}}$} & \multicolumn{2}{c|}{$R=7,75$} \\
\hline Группа/Group & I & II & III \\
\hline$h_{i}$ & $0,2-0,5$ & $1,0-1,5$ & $2,0-2,5$ \\
\hline$B_{i}$ & $3,2-5,48$ & $5,49-8,48$ & $8,48-10,5$ \\
\hline$S$ & $9-18$ & $19-30$ & $31-47$ \\
\hline
\end{tabular}

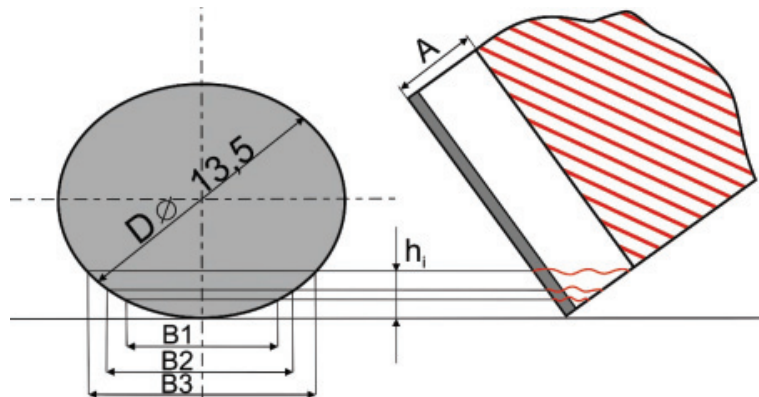

Puс. 4. Схема образования сколов при различных значениях В и $h$

Fig. 4. Scheme of formation of breakdowns at different values of $B$ and $h$

Пусть долото диаметром 215 мм, вооруженное 56 пластинами PDC, бурило породу VIII категории буримости $\left(P_{\mathrm{r}}=920 \mathrm{MПа)} \mathrm{при} \mathrm{осевой} \mathrm{нагрузке}\right.$ $P_{\text {ос }}=200 \mathrm{\kappa H}$, при этом на режущих PDC образовалось $15 \%$ сколов.

1. Определяем, сколько образовалось сколов на 56 пластинах

$$
n=\frac{56 \times 15}{100}=9 \text { сколов. }
$$

2. Из них крупных сколов - $10 \% ; n_{\mathrm{k}}=1$ скол с общей площадью:

$$
\sum S_{\mathrm{K}}=n_{\mathrm{K}} S_{\mathrm{K}}=36 \mathrm{MM}^{2},
$$

где $S_{\kappa}=\frac{31+42}{2}=36$ мм² $^{2}$ средний размер площади крупного скола.

3. Средних сколов $-30 \% ; n_{\mathrm{cp}}=2,5$ сколов с общей площадью:

$$
\sum S_{\mathrm{cp}}=2,5 \times 25=62 \mathrm{MM}^{2}
$$

где $S_{\text {ср }}=\frac{19+30}{2}=25$ мм² $^{2}$ средний размер площади среднего скола.

4. Мелких сколов $-60 \%, n_{\mathrm{m}}=5$ сколов с общей площадью:

$$
\sum S_{\mathrm{M}}=5 \times 13,5=68 \mathrm{MM}^{2},
$$


где $S_{\mathrm{m}}=\frac{9+18}{2}=13,5$ мм² $^{2}$ средний размер площади мелкого скола.

5. Общая площадь сколов

$$
\sum S_{\text {ск }}=68+62+36=166 \mathrm{мm}^{2} .
$$

Известно, что на отработанных долотах количество изношенных и поломанных режущих элементов примерно одинаково, тогда суммарная площадь затупления:

$$
\sum F_{\text {зат }}=\lambda \sum S_{\text {ск }}=332 \mathrm{MM}^{2} .
$$
была

При этом удельная нагрузка на режущих $\mathrm{PDC}$

$$
P_{\text {уд }}=\frac{P_{\text {ос }}}{\sum F_{\text {зат }}}=\frac{200000}{332}=602 \frac{H}{\mathrm{MM}^{2}}=602 \mathrm{M \Pi а,}
$$

где $P_{\text {ос }}=200 \mathrm{\kappa H}$ - осевая нагрузка на долото.

Механическая скорость бурения при этом составила:

$$
V_{\text {мб }}=V_{0} \frac{P_{\text {уд }}}{P_{\mathrm{K}}}=4,7 \frac{602}{920}=5,07 \frac{\mathrm{MM}}{\tilde{\mathrm{n}}}=11 \mathrm{M} / \mathrm{ч},
$$

где $V_{0}=4,7 \mathrm{~mm} / \mathrm{c}$ - модуль скорости для породы VIII категории буримости с $P_{\mathrm{k}}=920$ МПа.

Полученные результаты показывают высокую сходимость расчетного метода $\left(V_{\mathrm{w}}=11 \mathrm{~m} /\right.$ ч) и экспериментального определения механической скорости бурения $(V=10,3 \mathrm{~m} /$ ч) с учетом износа и поломок режущих элементов долот.

Преимущественное влияние крутильных и продольных колебания на образование сколов PDC по передней и задней грани подсказывает направление и поиск мероприятий по предупреждению поломок.

Для предупреждения возникновения крутильных колебаний необходимо бурильную колонну разгрузить от крутящего момента, передаваемого от ротора или ВЗД на буровое долото и оснастить режущие лопасти пластинами PDC с выпуклой передней гранью, способными ограничивать глубину внедрения резцов и гасить продольные колебания.

Для предупреждения возникновения крутильных колебаний и уменьшения износа периферийных режущих элементов на кафедре НТиТ (Нефтегазовые техника и технологии) ЮРГПУ (НПИ) было разработано двухъярусное долото со встречным вращением ярусов (патент РФ № 2445433).

При бурении скважин со сложным чередованием песчаников, алевролитов, с глинистыми прослоями, при переходах от крепких пород к мягким происходит резкое увеличение толщины срезаемого слоя и увеличение нагрузки, действующей на переднюю грань PDC (способную вызвать крутильные и продольные колебания в бурильной колонне).

Для предупреждения резкого внедрения долота в породу целесообразно оснащать лопасти долота пластинами PDC с выпуклой передней гранью.

На рис. 5 показана схема взаимодействия PDC с выпуклой и плоской передней гранью с породой.
Так, при бурении породы VIII категории с $P_{\mathrm{k}}=920 \mathrm{MM}^{2}$ с толщиной срезаемого слоя $h=1 \mathrm{Mм}$ при осевой нагрузке $4780 \mathrm{H}$ на PDC диаметром 13,5 мм при переходе на породу VI категории с $P_{\mathrm{k}}=650$ МПа режущий элемент войдет в породу на глубину $h=4,5$ мм. При этом произойдет резкое увеличение усилий резания, а следовательно, и крутящего момента на долоте.

II

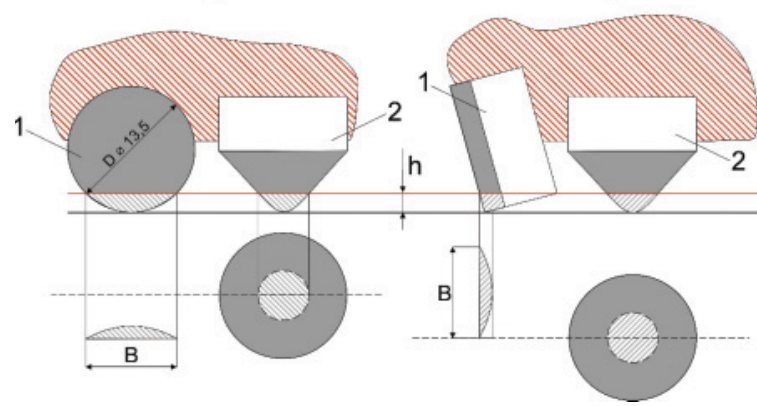

Puc.5. Схема расположения пластин PDC на лопасти долота: I - вид спереди пластин: 1 - с плоской; 2 - с выпуклой передней гранью; II - вид сбоку пластин: 1 - с плоской; 2 с выпуклой передней гранью

Fig. 5. Layout of the PDC plates on the bit blade: I - front view of plates: 1 - with flat; 2 - with convex front face; II - side view of plates: 1 - with flat; 2 - with convex front face

При установке на режущей лопасти пластин PDC с выпуклой передней гранью в виде круглого конуса с основанием $\varnothing 11$ мм, имеющего максимальную площадь контакта с породой $F_{2}=80$ мм $^{2}$, появляется возможность погасить на породе с $P_{\mathrm{k}}=650$ МПа осевую нагрузку 52 кН (5200 кг).

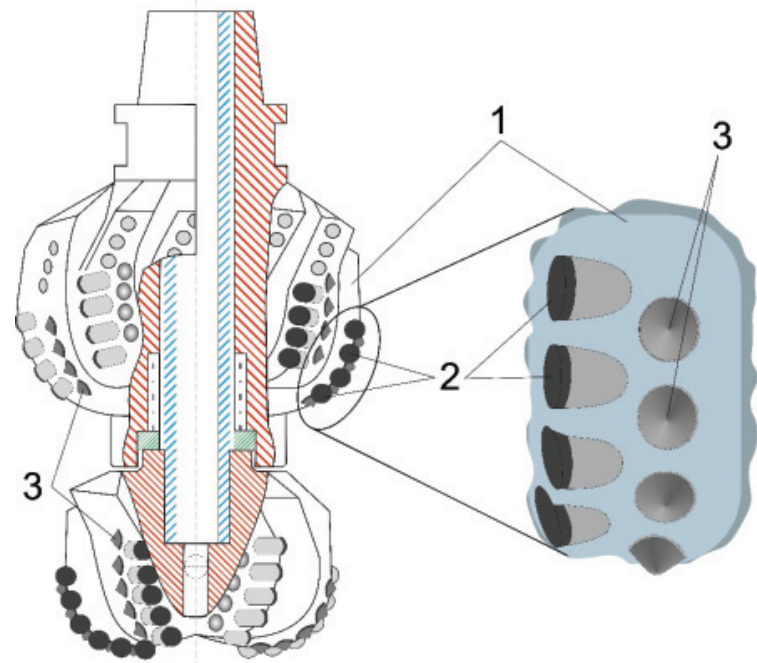

Pис. 6. Пример арлирования лопасти долота пластинали РDC: 1 - лопасть, 2-PDC с плоской передней гранью; 3 - РDC с выпуклой передней гранью

Fig. 6. Example of blade bit reinforcement with PDC plates: 1 is the blade, 2 is the PDC with flat front face; 3 is the PDC with convex front face

Тогда при переходе от породы с $P_{\mathrm{r}}=920 \mathrm{MПа} \mathrm{на}$ породу с $P_{\mathrm{k}}=650$ МПа режущий элемент, срезаю- 
щий на крепкой породе слой толщиной $1 \mathrm{MM}$, в мягкую породу войдет всего на 1,5 мм, т. к. основную часть осевой нагрузки на $\mathrm{PDC}$, равной 4780 кН, примет на себя выпуклая передняя грань круглого конуса.

По результатам выполненных исследований подана заявка на «Двухъярусное долото со встречным вращением ярусов, режущие лопасти которых оснащены пластинами PDC с плоской и выпуклой передними гранями, предупреждающими возникновение крутильных и продольных автоколебаний в бурильной колонне». На рис. 6 показан общий вид долота и пример армированных режущих лопастей - 1 долота пластинами PDC с плоской -2 и выпуклой -3 передними гранями.

\section{СПИСОК ЛИТЕРАТУРЫ}

1. Нескоромных В.В., Борисов К.И. Аналитическое исследование процесса резания-скалывания горной породы долотом с резцами $\mathrm{PDC} / /$ Известия Томского политехнического университета. - 2013. - Т. 323. - № 1. - С. 191-195.

2. Hossain M.E., Al-Majed A.A. Fundamentals of sustainable drilling engineering. - Salem, MA: Scrivener Publ., 2015. - 754 p. DOI: $10.1002 / 9781119100300$.

3. Третьяк А.А., Литкевич Ю.Ф., Асеева А.Е. Разработка методики расчёта наработки породоразрушающего инструмента с алмазнотвердосплавным вооружением // Строительство нефтяных и газовых скважин на суше и на море. - 2010. - № 12. - С. 2-5.

4. Soares C., Daigle H., Gray K. Evaluation of PDC bit ROP models and the effect of rock strength on model coefficients // Journal of Natural Gas Science and Engineering. - 2016. - V. 34. P. 1225-1236. DOI: $10.1016 /$ j.jngse.2016.08.012.

5. Буровой породоразрушающий инструмент / В.И. Балаба, И.К. Бикбулатов, Г.И. Вышегородцева, Э.С. Гинзбург, В.Я. Кершенбаум, А.С. Оганов. - М.: Изд-во РГУ нефти и газа, 2013. - 251 с.

6. Лабораторные исследования поломок режущих элементов буровых долот, армированных алмазно-твердосплавными пластинами / А.А. Третьяк, Ю.Ф. Литкевич, А.Н. Гроссу, К.А. Борисов // Деловой журнал Neftegaz.ru. - 2018. - № 7. - С. 50-54.

7. Третьяк А.Я., Кузнецова А.В., Борисов К.А. Определение поломок резцов $\mathrm{PDC}$ с помощью регрессионного и нейросетевого моделирования // Иввестия Томского политехнического университета. Инжиниринг георесурсов. - 2019. - Т. 330. - № 5. - С. 169-177.

8. Инновационные подходы к конструированию высокоэффективного породоразрушающего инструмента / А.Я. Третьяк, В.В. Попов, А.Н. Гроссу, К.А. Борисов // Горный информационно-аналитический бюллетень. - 2017. - № 8. - С. 225-230,

9. Вопияков В.А., Посташ С.А., Колесников П.И. Возникновение автоколебаний бурильной колонны - критерии износа шарошечных долот // Бурение. - 1974. - № 8. - С. 23-25.

10. Симонов В.В., Юнин Е.К. Влияние колебательных процессов на работу бурильного инструмента. - М.: Недра, 1977. - 210 с.

11. Власюк В.И., Будюков Ю.Е., Спирин В.И. Технические средства и технологии для повышения качества бурения скважин. - Тула: Гриф и К, 2013. - 176 с.

\section{Выводы}

1. Для предупреждения возникновения крутильных колебаний необходимо бурильную колонну разгрузить от крутящего момента, передаваемого от ротора или винтового забойного двигателя на буровое долото, и оснастить режущие лопасти пластинами PDC с выпуклой передней гранью.

2. Площадь сколов $\Sigma S$ можно рассматривать как образование дополнительных площадок затупления, определяющих удельную нагрузку на режущих кромках PDC.

3. По результатам выполненных исследований подана заявка на «Двухъярусное долото со встречным вращением ярусов, режущие лопасти которых оснащены пластинами PDC с плоской и выпуклой передними гранями» .

12. Ресурсосберегающая технология алмазного бурения в сложных геологических условиях / Н.В. Соловьев, В.Ф. Чихоткин, Р.К. Богданов, А.П. Закора. - М.: Изд-во ВНИИОЭНГ, 1997. - 329 с.

13. A new methodology for optimization and prediction of rate of penetration during drilling operations / Y. Zhao, A. Noorbakhsh, M. Koopialipoor, A. Azizi, M.M. Tahir // Engineering with Computers. - 2019. URL: https://link.springer.com/content/pdf/10.1007 \% 2Fs00366-019-00715-2.pdf (дата обращения 11.10.2019). DOI: 10.1007/s00366-019-00715-2.

14. Нескоромных В.В., Пушмин П.С. Методика оптимальных параметров режима и условий бурения скважин // Известия Сибирского отделения Секции наук о Земле РАЕН. - 2011. № 1 (38). - C. 151-157.

15. A new method of combined rock drilling / T. Jiren, L. Yiyu, G. Zhaolong, X. Binwei, S. Huijuan et al. // International Journal of Mining Science and Technology. - 2014. - V. 24. - Iss. 1. P. $1-6$.

16. Влияние угла установки резца PDC лопастного долота на механическую скорость бурения скважин в перемежающихся по твердости горных породах / Ю.А. Арсентьев, Н.В. Соловьев, А.П. Назаров, А.М. Лимитовский / Г Горный журнал. - 2018. № $11 .-$ C. $47-50$.

17. Теоретический метод обоснования конструктивных параметров долот режуще-скалывающего действия / Н.В. Соловьев, Ю.А. Арсентьев, Т.Х. Нгуен, Х.Н. Курбанов // Инженер-нефтяник. - 2015. - № 3. - С. 16-24.

18. Соловьев Н.В., Бейкель В.А. Состояние и пути повышения эффективности техники и технологии бурения скважин при выполнении геологоразведочных работ / Известия высших учебных заведений. Геология и разведка. - 2013. - № 1. - С. 50-56.

19. Нескоромных В.В. Результаты экспериментальных исследований буримости анизотропной горной породы // Известия высших учебных заведений. Геология и разведка. - 2013. № 6. - C. $81-85$.

20. Navarro-Lopez E.M., Cortes D. Avoiding harmful oscillations in a drillstring through dynamical analysis // Journal of Sound and Vibration. - 2007. - V. 307. - № 1-2. - P. 152-171.

Поступила 15.10.2019 2.

\section{Информация об авторах}

Tpemьлк A.A., доктор технических наук, доцент, профессор кафедры нефтегазовой техники и технологии Южно-Российского государственного политехнического университета (НПИ) им. М.И. Платова.

Литкевич Ю.Ф., кандидат технических наук, доцент, доцент кафедры нефтегазовой техники и технологии Южно-Российского государственного политехнического университета (НПИ) им. М.И. Платова.

Борисов $\boldsymbol{K} . \boldsymbol{A}$., ассистент кафедры нефтегазовой техники и технологии Южно-Российского государственного политехнического университета (НПИ) им. М.И. Платова. 


\title{
INFLUENCE OF TORSIONAL AND LONGITUDINAL VIBRATIONS ON DRILLING SPEED AND FORMATION OF BREAKDOWNS OF CUTTING ELEMENTS OF PDC-REINFORCED DRILL BITS
}

\author{
Alexander A. Tretyak', \\ 13050465@mail.ru \\ Yuriy F. Litkevich', \\ 13050465@mail.ru \\ Konstantin A. Borisov', \\ 13020165@mail.ru \\ ' Platov South-Russian State Polytechnic University (NPI), \\ 132, Prosveshcheniya street, Novocherkassk, 346428, Russia.
}

The relevance. Currently, for construction of oil and gas wells, the most effective tool are bits reinforced with PDC (polycrystalline diamond cutters). These bits work on cutting-chipping principle, as the cutting is the most effective among all the mechanisms of rock destruction, due to the fact that the tensile strength of the rock and chipping is much less than its compressive strength. The analysis of the state of spent drill bits reinforced with PDC plates shows that they work out their life not fully, as a part of the cutting PDC elements fails due to chipping. The variety of forms of chips in shape and size requires classification, identification of the reasons of occurrence and determination of loads that lead to their occurrence. In addition, the scrapping of plates or their loss significantly affects the final technical and economic performance of drilling exploration and production wells. Solving the issues of improving the quality of bits by reducing the number of breakdowns will help to improve the economic efficiency of work in extraction and exploration of minerals.

The aim of the study is the sizing platform chips for possible classification depending on the thickness of the shear layer of rock cutting element, and determining the causes of torsional and longitudinal vibrations in the drill string, causing breakage of the PDC offered a constructive change of drill bits reinforced PDC plates, warning the appearance of self-oscillations in the drill string.

Objects: cutting elements of drill bits reinforced with PDC plates with a flat front face and PDC with a convex front face, chips of PDC plates on drill bits arising during drilling.

Methods: experimental and analytical method of research on laboratory samples and on spent drill bits reinforced with PDC plates.

Result. Based on the analysis and generalization of the results of the laboratory studies of the PDC plate breakdown occurrence causes and their nature the authors have developed the number of technical and technological solutions that prevent the occurrence of torsional and longitudinal self-oscillations in the drill string, and increase the efficiency of rock-cutting tools reinforced with PDC plates.

\section{Key words:}

Laboratory research, waste drill bits, PDC breakdowns, torsional vibrations, breakdown from the action of forces on the front face, breakdown from the action of forces on the back face, torsional wave, longitudinal wave, energy of inelastic impact, mineral exploration.

\section{REFERENCES}

1. Neskoromnykh V.V., Borisov K.I. Analytical study of cutting process-splitting rock bit with PDC cutters. Bulletin of the Tomsk Polytechnic University, 2013, vol. 323, no. 1, pp. 191-195. In Rus.

2. Hossain M.E., Al-Majed A.A. Fundamentals of Sustainable Drilling Engineering. Salem, MA, Scrivener Publ., 2015. 754 p. DOI: 10.1002/9781119100300.

3. Tretyak A.A., Litkevich Yu.F., Aseeva A.E. Razrabotka metodiki rascheta narabotki porodorazrushayushchego instrumenta s almazno-tverdosplavnym vooruzheniem [Development of methods for calculating the operating time of rock-cutting tools with diamond-carbide weapons]. Stroitelstvo neftyanykh $i$ gazovykh skvazhin na sushe i na more, 2010, no. 12, pp. 2-5.

4. Soares C., Daigle H., Gray K. Evaluation of PDC bit ROP models and the effect of rock strength on model coefficients. Journal of Natural Gas Science and Engineering, 2016, vol. 34, pp. 1225-1236. D0I: 10.1016/j.jngse.2016.08.012.

5. Balaba V.I., Bikbulatov I.K., Vyshegorodtseva G.I., Ginzburg E.S., Kershenbaum V.Ya., Oganov A.S. Burovoy porodorazrushayushchiy instrument [Drilling rock cutting tools]. Moscow, National University of Oil and Gas Publ., 2013. 251 p.

6. Tretyak A.A., Litkevich Yu.F., Grossu A.N., Borisov K.A. Laboratornye issledovaniya polomok rezhushchikh elementov burovykh dolot, armirovannykh almazno-tverdosplavnymi plastinami [Laboratory studies of breakdowns of cutting elements of drill bits reinforced with diamond-carbide plates]. Delovoy zhurnal Neftegaz.ru, 2018, no. 7, pp. 50-54.

7. Tretyak A.Ya., Kuznetsova A.V., Borisov K.A. Determination of PDC cutter breakdowns using regression and neural network modeling. Bulletin of the Tomsk Polytechnic University. Geo Assets Engineering, 2019, vol. 330, no. 5, pp. 169-177. In Rus.

8. Tretyak A.Ya., Popov V.V., Grossu A.N., Borisov K.A. Innovative approaches to designing highly efficient rock-breaking tool. $\mathrm{Mi}$ ning informational and analytical bulletin (scientific and technical journal), 2017, no. 8, pp. 225-230. In Rus.

9. Vopiyakov V.A., Postash S.A., Kolesnikov P.I. Vozniknovenie avtokolebaniy burilnoy kolonny - kriterii iznosa sharoshechnykh dolot [Occurrence of self-oscillations of the drill string - criteria for wear of roller bits]. Burenie, 1974, no. 8, pp. 23-25.

10. Simonov V.V., Yunin E.K. Vliyanie kolebatelnykh protsessov na rabotu burilnogo instrumenta [0scillatory processes influence on drilling tool operation]. Moscow, Nedra Publ., 1977. 210 p.

11. Vlasyuk V.I., Budyukov Yu.E., Spirin V.I. Tekhnicheskie sredstva i tekhnologii dlya povysheniya kachestva bureniya skvazhin [Technical means and technologies to improve the quality of drilling]. Tula, Grif i K Publ., 2013. 176 p.

12. Solovev N.V., Chikhotkin V.F., Bogdanov R.K., Zakora A.P. Resursosberegayushchaya tekhnologiya almaznogo bureniya $v$ slozhnykh geologicheskikh usloviyakh [Resource-saving technology of diamond drilling in difficult geological conditions]. Moscow, VNIIOENG Publ., 1997. 329 p. 
13. Zhao Y., Noorbakhsh A., Koopialipoor M., Azizi A., Tahir M.M. A new methodology for optimization and prediction of rate of penetration during drilling operations. Engineering with Computers, 2019. Available at: https://link.springer.com/content/pdf $/ 10.1007 \%$ 2Fs00366-019-00715-2.pdf (accessed 11 October 2019). DOI: $10.1007 / \mathrm{s} 00366-019-00715-2$.

14. Neskoromnyh V.V., Pushmin P.S. Methods to determine optimum parameters of the mode and conditions of borehole drilling. Proceedings of the Siberian branch of the section of Earth Sciences RAEN, 2011, no. 1, pp. 151-157. In Rus.

15. Jiren T., Yiyu L., Zhaolong G., Binwei X., Huijuan S. A new method of combined rock drilling. International Journal of Mining Science and Technology, 2014, vol. 24, Iss. 1, pp. 1-6.

16. Arsentiev Yu.A., Soloviev N.V., Nazarov A.P., Limitovsky A.M. Effect of PDC cutter rake on penetration rate of wing bit drilling in variable hardness rocks. Gorny zhurnal, 2018, no. 11, pp. 47-50. In Rus. D0I: 10.17580/gzh.2018.11.08
17. Solovev N.V., Arsentev Yu.A., Nguen T.X., Kurbanov X.N. Thinking of parameters for cutting-shearing type drilling bit design. Inzhener-neftyanik, 2015, no. 3, pp. 16-24.

18. Solovev N.V., Beikel V.A. Statement and ways to increase the efficiency of drilling techniques and technologies in geological exploration works. Proceedings of Higher Schools, Geology and Exploration, 2013, no. 1, pp. 50-56. In Rus.

19. Neskoromnykh V.V. Results of the pilot studies of drilling capacity of anisotropic rock. Proceedings of Higher Schools, Geology and Exploration, 2013, no. 6, pp. 81-85. In Rus.

20. Navarro-Lopez E.M., Cortes D. Avoiding harmful oscillations in a drillstring through dynamical analysis. Journal of Sound and Vibration, 2007, vol. 307, no. 1-2, pp. 152-171.

Received: 15 October 2019.

\section{Information about the authors}

Alexander A. Tretyak, Dr. Sc., associate professor, Platov South-Russian State Polytechnic University (NPI).

Yuriy F. Litkevich, Cand Sc., associate professor, Platov South-Russian State Polytechnic University (NPI).

Konstantin A. Borisov, assistant, Platov South-Russian State Polytechnic University (NPI). 